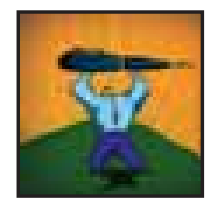

Quarterly Letters

\section{An Effective Stimulus for Change}

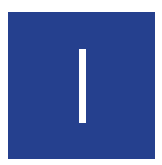

read the article entitled "Benchmarking Comparisons of the Efficiency and Quality of Care of Canadian Teaching Hospitals" by Helyar et al. (Hospital Quarterly, Spring 1998) with great interest. As Chief of Staff of one of the Canadian teaching hospitals, I am charged by my Board of Trustees with responsibility for the quality of medical care provided to all patients. Like many of my colleagues, I am concerned that the attrition of healthcare resources through fiscal constraint will ultimately lead to deterioration in the quality of care deliverable to our teaching hospital patients, particularly when the alternative community-based facilities and resources are not yet in place.

"Benchmarking" and "best practices" are words in common use at our hospital and their underlying concepts have provided an effective stimulus for change. To ensure that benchmarking continues to be an effective stimulus for change, physicians and administrators would do well to remind themselves of the process of benchmarking, as quoted by Helyar et al.: "In healthcare, the key to benchmarking rests with understanding and improving the underlying processes and practices that drive quality, cost and clinical excellence. Benchmarking helps to determine how other organizations have achieved exemplary performance and suggests a method for adapting benchmark performance to one's own organization." And, later in the discussion: "The goal of the ACTH/HayGroup Benchmarking Comparison of Canadian Teaching Hospitals is to identify high-performing clinical and operational processes that can be emulated to improve the efficiency and quality of hospital services across Canada."
It is not enough to look within one's own institution for efficiencies or changes in process. It is necessary to examine how the high-performing hospitals provide care and what processes are used to achieve the benchmark indicator. The data provided in the article are just that figures illustrating the variability of performance for each of the indicators. Those seeking to meet the benchmark will need information as to process. How is care provided in Hospital C, with the short ALOS for stroke discharges (Exhibit 4)? Is this the result of availability of a stroke rehabilitation unit or rehabilitation carried out elsewhere in a non-acute setting? Is the short length of stay an artifact caused by the opportunity to transfer the patient? In this day of the "integrated system", it would be appropriate to count all days during which care is delivered to the patient while an in-patient, whatever the institution. The same point can be made with regard to knee replacement (Exhibit 5) which shows two groups of hospitals, one with ALOS of 7-8 days, the other (said to have lower case volumes) with ALOS over 10 days. Those hospitals with high knee replacement volumes might be expected to function in conjunction with a rehabilitation centre, however, whether the days spent in the rehabilitation centre have been counted in the ALOS is unclear.

To avoid any potential for the ALOS numbers to become a shell game, it would be very useful to capture and display all institution-based patient days, whether in the teaching hospital or another institution, for all those CMGs where part of the care required is likely to be provided in non-acute settings. This will enable non-teaching hospital resources and costs to be identi- fied and compared. "Benchmarking," to be a real value as we restructure to provide more care outside the hospital, must be able to take into account both the resources used, both hospital and non-hospital, and the quality of care delivered, both hospital and non-hospital. There is, inevitably, an emphasis on efficiency measures in this article. Inevitable because of the data sources, on the one hand, and because of the difficulty of defining quality of care on the other. Clinical and Operational Efficiencies are not necessarily indicators of the quality of care. Defining quality of care by two indicators, Risk Adjusted Complication Ratio and Risk Adjusted Mortality Index, as done in the article, is a start, but the conclusions are so surprising that the authors have to acknowledge the documentation issues as well as the possible impact of structural changes to the healthcare system on the quality of care provided. The Hospital Accreditation Standards define eight Dimensions of quality: Efficiency, Effectiveness, Accessibility, Acceptability, Appropriateness, Safety/ Risk, Competence, and Continuity. Many of these can be interpreted as relating to the performance of the institution in delivering care, not of the quality of care delivered to the patients.

I applaud the Association of Canadian Teaching Hospitals and the HayGroup for what they have achieved so far, particularly in describing Clinical and Operational Efficiency, but I urge them to go further, to set up a system to define and measure quality of care in terms of deliverables that have been shown to effect health outcomes. In this time of "evidence-based medicine" with the growing popularity of "care paths," we should be able to define quality of care differently, and measure it. This may 
need to be done by individual CMG. In myocardial infarction, for example, the "door to needle time" is an indication of compliance with an evidence-based standard of care, and for the same condition, the proportion of patients discharged on medications considered appropriate for the reduction of morbid- ity and mortality post MI. This type of information can be obtained currently, with the expenditure of many human hours (e.g., the MACSTRAK Project), but should in the future be more easily accessible via computerized medical records or, in the shorter term, with linkage of key elements such as the pharmacy database and the diagnostic database information. IQ

A.C.P. Powles, M.B., Ch.B. Chief of Staff, St. Joseph's Hospital Professor of Medicine Faculty of Health Science McMaster University

\section{... a letter to the publisher}

t was a pleasure to meet you when Robert's art was recently exhibited in Toronto. I hope the images of Robert you use in Hospital Quarterly will create interest and bring new understanding.

When we spoke you kindly suggested you would try to promote the work of our Foundation. There are two projects in particular that we would like to emphasize at this time:

1. To place a beautiful, large reproduction of "Hug" in many Canadian hospitals. The size of this reproduction would be approximately 3 feet in height by $11 / 2$ feet in width plus frame with a small plaque placed at the bottom of the painting indicating the sponsor's name. This painting impresses people everywhere it is seen as it vividly depicts two healing forces at work - the healing force of medicine and the healing power of love. No matter how sick you may be, when someone loves you life is special, each day is precious.

Would one of your advertisers, such as a national bank, be interested in having this image placed in hospitals across the country? In each town or city where the bank has a branch, if they would place this impressive painting in the local hospital, with their name attached, it would be a fine public relations gesture for them and an asset to the hospital. What a wonderful contribution it would be for some donor to place "Hug" in

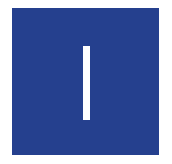

1000 Canadian hospitals, and if the local branches of a national bank would fund the cost of placing it in their communities, the cost would be minimal at any one site, about $\$ 300$ including donor's plaque.

2. Numerous physicians have said Robert's book Illness and Healing should be placed in the hands of all students entering medical school as it would show them the importance of understanding what cancer is like from the patient's perspective. There are 16 medical schools in Canada, and the cost of presenting this book to first year students, in either a French or English edition, would be about $\$ 2000$ per medical school. The donor's name could be placed on the opening page of the book.

I think these are two wonderful projects and would give a quality profile to sponsors. It would be much appreciated if you could interest some sponsors to underwrite these projects. IQ

\section{With all good wishes. William Pope Robert Pope Foundation $902684-9129$}

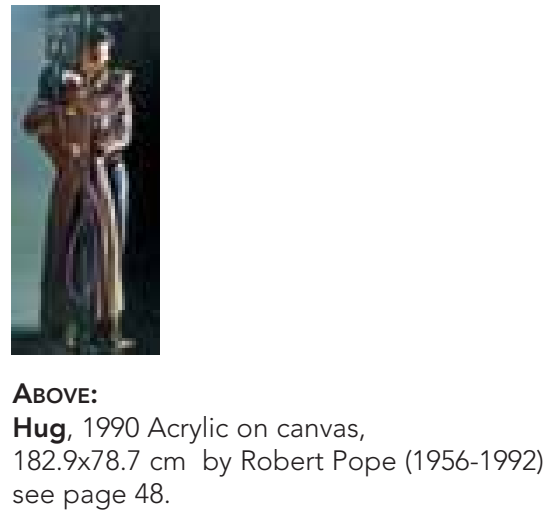

Letters to Hospital Quarterly can be emailed to notes@longwoods.com or faxed to the editors at 416 368-6292. 


\section{Reform in Ontario ...}

W hen our government took office three years ago, we faced a daunting challenge in the health system. It had been designed for the needs of the 1950s to the $1970 \mathrm{~s}$, but was clearly not measuring up to demands of the 1990s: It was not responding to the extraordinary advances in technology, the marked trend toward shorter hospital stays, nor to the rapidly changing demographics of Ontario's population. It is for this reason that we embarked on the most ambitious reform of our health system ever undertaken in Ontario.

A key component of this reform includes the restructuring of our health services with a focus on our hospitals. The arms-length Health Services Restructuring Commission has almost concluded its assessment stage; we are now moving into the implementation of reform. The Commission has issued binding directions on how a reconfigured hospital system should look in individual communities to ensure enhanced access to priority services, a continuum of institutional and community-based care, and recommendations on what level of reinvestment is required to support the reformed system.

Any savings realized through the restructuring of our hospitals are reinvested back into the system. To-date, we have put more than $\$ 400$ million back into hospital-based programs. We also continue to reinvest in acute-care programs in high-growth areas of the province, especially the rapidly growing 905 area surrounding Toronto. We will continue to work with our public hospitals throughout the restructuring period to ensure that the delivery of highquality patient care continues to be our top priority. To assist hospitals during this period, we have also dedicated more than $\$ 2$ billion in funding to provide hospitals with the support they need with their restructuring costs.

In this year's provincial budget, Finance Minister Ernie Eves announced a package of new health-system initiatives. They include establishing a Nursing Task Force to look at issues affecting the nursing profession, providing $\$ 300$ million in renewal funding for medical equipment to assist hospitals with Year 2000 issues, adding 20,000 senior-care beds and upgrading an additional 13,000 beds, and dedicating $\$ 55$ million to create 1700 temporary long-term care beds in existing hospital space to ease acute-care pressures and improve patient flow. Our government also responded to the recommendations of the Emergency Services Working Group on hospital emergency room pressures by announcing $\$ 75$ million to support the opening of temporary hospital beds during periods of peak demand. These actions demonstrate "There are too many dollars in the hospital system our government's tied up in duplication and inefficiency, in bricks commitment to and mortar rather than people.

working proactively with our hospitals to ensure that our health system delivers a continuum of care that consistently meets the needs of patients.

All of these initiatives are part of a plan to reform our health system. The plan entails the greatest reinvestment in health services this province has ever seen, with reinvestment to-date already totaling well over $\$ 3$ billion. The plan entails building on the existing excellence of our health services to create a system tailored to the needs of Ontarians well into the 21 st century. This means ensuring that the appropriate services are there when people need them, at every stage of their lives, as close to home as possible. It means an integrated, seamless system of health services to help make Ontario the best place to live and work in North
Hospital Quarterly has invited Canada's health ministers to share their thoughts on strategic planning for their provinces. In this issue Hon. Elizabeth Witmer, Ontario, and the Hon. James Smith, Nova Scotia, share their visions.

America. It means reinvesting in critical care services and specialized programs.

In the priority area of cardiac surgeries and facilities, improved access is demonstrated by the number of completed cardiac cases for adult Ontarians. Completed procedures were 12 percent greater in the first 10 months of the fiscal year than in the same period the previous year. The waiting time in January, 1998, was 29 per cent less than it was a year earlier. We have reinvested more than $\$ 65$ million in cardiac programs.

We've created Cancer Care Ontario, 
placed on hospitals at a time when more and more patients can receive a broader range of health services in their communities or homes. This frees up hospitals to provide emergency services, acute medical care, conduct teaching and research duties, and perform other complex and specialized procedures.

Perhaps the most important component in an integrated system is the commitment and full participation of all the health care partners. From community volunteers to nurses, to surgeons, we appreciate the dedication of those who deliver health services with both skill and compassion, and those who support them in their efforts.

By working together we are transforming tomorrow's possibilities into today's certainties, and building a health system to meet the needs of our population in the 21 st century. IG

\section{Balancing Priorities in Nova Scotia}

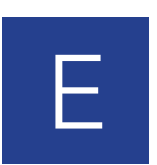

very jurisdiction is experiencing difficulty in coming to terms with the cost and sustainability of publicly funded health care. The issues that governments, health boards case providers and the tax payers face are complex.

With each new day, it seems, there is an opportunity to spend new dollars on a medical advance, a wonder drug, a technological invention, or a program that will address an unmet need. This at the same time as governments are challenged to continue funding the existing health care system at previous levels. The demand for funding in health care seems to be insatiable, notwithstanding that the ability to pay for health care is limited. And as any health care manager knows, the dilemma is not just economic. There are moral, ethical, and yes, political issues to consider in making resourceallocation choices. The stakes, on all counts, are very high, particularly in times of rising expectations and diminishing resources.

While we all enjoy what is arguably one of the best healthcare systems in the world, as Minister I sometimes wonder if the public thinks we are fixing a system that they don't perceive to be broken. Instead of being credited for shepherd- ing a fragmented and uncoordinated 30 year old systems into the next century, health reform is more likely to be associated with concerns about quality, access and adequacy of funding. Unlike almost any other social program, healthcare affects everyone in some way at some point in their lives. As a result, there are strongly held opinions about how the health care system should and shouldn't be run, and what is reasonable to expect a publicly funded program to provide.

We have also had a long tradition of funding and organizing the health care system along sectoral lines. Acute care, continuing care, mental health, addiction services and public health have tended to be regarded as programmatic solitude's, rather than as components of a well integrated continuum of service. Patients and health care providers understand very well how interconnected these parts of the continuum really are. After all, people don't present themselves as a collection of body parts requiring attention - they present themselves as persons and families who need care. But the way health care has been organized and funded in the past has belied such a person-centre approach. In fact, it has often frustrated it.

That is why when we contemplate such issues as appropriate levels of

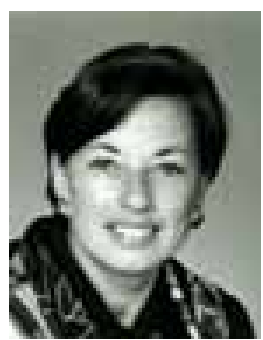

Hon. Elizabeth Witmer, Minister of Health, Ontario funding for hospitals, their role must be considered in the context of the broader health care system. How hospitals link with home care and long term care, building the community-based infrastructure for mental health and addiction services, and having the prehospital and emergency health service components working in a coordinated fashion requires more system-level thinking then ever before.

For example, in the past, it was not uncommon for a shortage of acute care beds to be responded to with the opening of additional beds, a solution that appears on the face of things to be the most logical, but, we learned, was not always the most appropriate in responding to the real needs of the community. Indeed, it may be as likely that the solution lies in building greater capacity for home care services, making more long term care beds available - or improving discharge planning processes and links with other parts of the health care system. Often, additional inpatient beds only treated the symptom, while actually making the real problem worse. Consideration of how all parts of the health care system can work together to better meet the needs of patients and their families is what integrated service planning and delivery is all about.

While there is clearly opportunity to improve, issues of quality and access to 


\section{CASE MIX CONFERENCE}

\section{Moving From Data to}

Decisions With

Case Mix

\section{September 14-15, 1998 \\ Canmore, Alberta}

Moving from Data to Decisions with Case Mix is a national conference designed to bring you up-to-date on current case mix tools and their applications.

This two-day event takes place from September 14 to 15 in Canmore, Alberta and is organized by the Canadian Institute for Health Information (CIHI), in collaboration with Alberta Health.

Topics to be addressed include:

- current case mix tools and their applications;

- ways in which Canadian health care organizations can use case mix tools to influence the quality of health care delivered to their population; and

- initiatives currently under way in Canada that take case mix tools in new directions.

\section{Who Should Attend?}

This conference will be of interest to health service executives, health and policy planners, researchers, physicians, utilization managers and health information specialists who want to implement case mix in their decision making.

\section{For more information, call our Education Department.}

Canadian Institute for Health Information 377 Dalhousie Street, Suite 200 Ottawa, Ontario K1N 9N8 Tel. (613) 241-7860 Fax (613) 241-8120 www.cihi.ca services still exist, all provinces are challenged to determine whether the level of funding for the health care system that the public has come to expect is adequate. Nearly every jurisdiction has embarked upon the journey or regionalization, in part to achieve the administrative economies of scale that larger service units can often achieve. It is generally agreed, however, that the anticipated savings from these management consolidations have now been exhausted. Changing demographics that will result in health service volume increases, new drugs and technologies, and medical advances will all require net new dollars to existing healthcare budgets. It will not become less expensive over time to provide the same level of service however efficient the administration of those services may be.

When entering into the debate about appropriate levels of funding for healthcare services, government and the public alike will need to consider the even broader context; the economic health of the province and the communities of which it is composed. Health and social planners and economists alike all seem to agree that many areas are faced with the "Catch-22" - those areas which suffer the worst health status and require the most services are the areas which are least capable of paying for them. The wealthier you are, the healthier you are is truism that greatly challenges those provinces which experience some of the biggest socio-economic problems and associated morbidity and mortality statistics. If the healthcare system, while attempting to respond to the consequences of a struggling economy also contributes to poor economic health, the cycle sees no apparent end. Finding that balance will be among the most difficult and important contributions any government could make.

At the end of the day, the public wants to be assured that the healthcare system will be there for them when they need it. Having timely access to quality services; at a cost that is affordable the taxpayer, is our obligation. Ensuring that funds for service are allocated based on the principle of coordination and integration is what will achieve both value for money and relevance for the patient, ultimately leading to a sustainable, publicly funded health care system. IQ

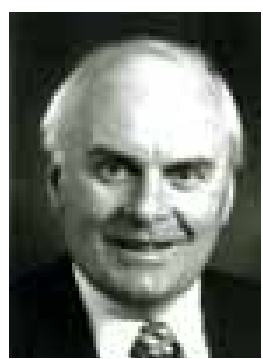

Hon. James Smith

Minister of Health, Nova Scotia

JAMES SMITH 